\title{
Thixoforming of Stellite Powder Compacts
}

\author{
S C Hogg ${ }^{1}, \mathrm{H}$ V Atkinson ${ }^{2}$ and P Kapranos ${ }^{3}$ \\ ${ }^{I}$ Now at Institute of PolymerTechnology and Materials Engineering, Loughborough University, \\ Loughborough, LE11 3TU, UK, formerly at the Department of Engineering Materials, University of \\ Sheffield, Mappin Street, Sheffield S1 3JD, UK. Email: s.c.hogg@lboro.ac.uk \\ ${ }^{2}$ Now at the Department of Engineering, University of Leicester, University Rd., Leicester LE1 7RH, \\ UK, formerly at the Department of Engineering Materials, University of Sheffield, Mappin Street, \\ Sheffield S1 3JD, UK.Email: hva2@le.ac.uk \\ 3 Department of Engineering Materials, University of Sheffield, Mappin Street, Sheffield S1 3JD, UK. \\ Email:p.kapranos@shef.ac.uk
}

\begin{abstract}
Thixoforming involves processing metallic alloys in the semi-solid state. The process requires the microstructure to be spheroidal when part-solid and part-liquid i.e. to consist of solid spheroids surrounded by liquid. The aim of this work was to investigate whether powder compacts can be used as feedstock for thixoforming and whether the consolidating pressure in the thixoformer can be used to remove porosity from the compact. The powder compacts were made from stellite 6 and stellite 21 alloys, cobalt-based alloys widely used for e.g. manufacturing prostheses. Isothermal heat treatments of small samples in the consolidated state showed the optimum thixoforming temperature to be in the range $1340^{\circ} \mathrm{C}-1350^{\circ} \mathrm{C}$ for both materials. The alloys were thixoformed into graphite dies and flowed easily to fill the die. Porosity in the thixoformed components was lower than in the starting material. Hardness values at various positions along the radius of the thixoformed demonstrator component were above the specification for both alloys.
\end{abstract}

Keywords: Thixoforming; semi-solid processing; stellite; powders.

PACS: 62.20 Fe

\section{INTRODUCTION}

The shaping of an alloy in the semi-solid, rather than fully liquid state as in casting, or in the fully solid state as in forging, offers many advantages. These include energy savings, reduced die wear and a fine and homogeneous microstructure. Semi-solid processing utilizes the thixotropic behaviour of alloys in the semi-solid state; provided the microstructure consists of solid spheroids in a liquid matrix it will flow when sheared but thicken up again when allowed to stand [1]. Many aluminium and magnesium alloy components are now manufactured commercially by semi-solid processing. The challenge is to extend the application of the process to a wider range of materials including those which require higher temperature treatment and oxidize during reheating, such as the stellites. These are Co-Cr-based alloys which have excellent resistance to many forms of mechanical and chemical degradation over a wide temperature range [2]. They are used for a range of applications including power 
generation, automotive, aerospace and medical (eg. for prostheses). However, forming these materials into shape (including machining) is difficult because they are hard. Components are generally produced by casting or powder metallurgy. Here we set out to investigate whether consolidated and sintered billets can be shaped by thixoforming. Previous work using powder based thixoforming feedstock routes has concentrated on Al-based systems eg. $2124 \mathrm{Al}+\mathrm{SiC}_{\mathrm{p}}$ composites from cold compacted mechanically alloyed powder [3] and densified hypereutectic Al-Si [4]. Co-Cr alloys have previously been processed by thixoforming using sprayformed feedstock and material produced using a deformation/recrystallisation(RAP) route $[5,6]$ but this study represents the first using Co-Cr alloy thixoformable feedstock produced from powder.

\section{MATERIALS AND EXPERIMENTAL PROCEDURE}

The material was produced by spray atomizing followed by consolidation and sintering. The powder particle size is $<45 \mu \mathrm{m}$. Cylindrical slugs $(32 \mathrm{~mm} \Phi \mathrm{x} 40 \mathrm{~mm})$ of stellite 6 (S6) and stellite 21 (S21) alloy were supplied by Deloro Stellite. The melting range for stellite 6 is $1282-1393^{\circ} \mathrm{C}$ and for stellite $21,1338-1366^{\circ} \mathrm{C}$. The nominal compositions are given in Table 1. Stellite 6 has a high $\mathrm{C}$ content and exhibits excellent wear resistance. Stellite 21 has less $\mathrm{C}$ and additions of Mo to promote the formation of Mo carbides. This leaves more $\mathrm{Cr}$ in solution [2], and the material is more suited to applications where corrosion resistance is important.

\begin{tabular}{l|l|l|l|l|l|l|l|l|l} 
& $\mathrm{C}$ & $\mathrm{Cr}$ & $\mathrm{Fe}$ & $\mathrm{Mn}$ & $\mathrm{Mo}$ & $\mathrm{Si}$ & $\mathrm{W}$ & $\mathrm{Ni}$ & Co \\
\hline S6 & 1.15 & 27.8 & 3 & $1 \max$ & $1 \max$ & 1.15 & 4.5 & - & Bal. \\
\hline S21 & 0.25 & 28 & $2 \max$ & $1 \max$ & 5.5 & $2 \max$ & - & 2.5 & Bal.
\end{tabular}

Table 1. Nominal chemical compositions of stellite 6 and stellite 21 (all compositions are in $\mathrm{wt} \%$ unless otherwise stated).

Isothermal heat treatments of the samples were carried out in a vertical tube furnace in air. Samples were held isothermally for 5 minutes and quenched into water. The samples were polished to $0.25 \mu \mathrm{m}$ colloidal silica and examined optically and with image analysis. Thixoforming was carried out using the $100 \mathrm{kN}$ servo-hydraulic thixoforming press at the University of Sheffield with an injection velocity of $500 \mathrm{mms}^{-1}$. The dies were machined in-house from graphite. Reheating to the required temperature was accomplished using induction heating under a shielding atmosphere of either nitrogen or argon to avoid excessive oxidation of the surface of the samples during heating to the semi-solid state. The reheating time was $\sim 6$ minutes.

\section{RESULTS AND DISCUSSION}

\section{Microstructure of Starting Material and Isothermal Heat Treatments}

The as-received microstructures of S6 and S21 are given in Fig. 1. The porosity levels found using image analysis were $\sim 1$ area $\%$ for S6 and $\sim 7$ area $\%$ for the S21. 
Both microstructures consisted of a primary Co-rich matrix phase (fcc at the thixoforming temperature) plus carbide phases which typically consist of $\mathrm{M}_{6} \mathrm{C}, \mathrm{M}_{23} \mathrm{C}_{6}$ and/or $\mathrm{M}_{7} \mathrm{C}_{3}$ carbides [7].
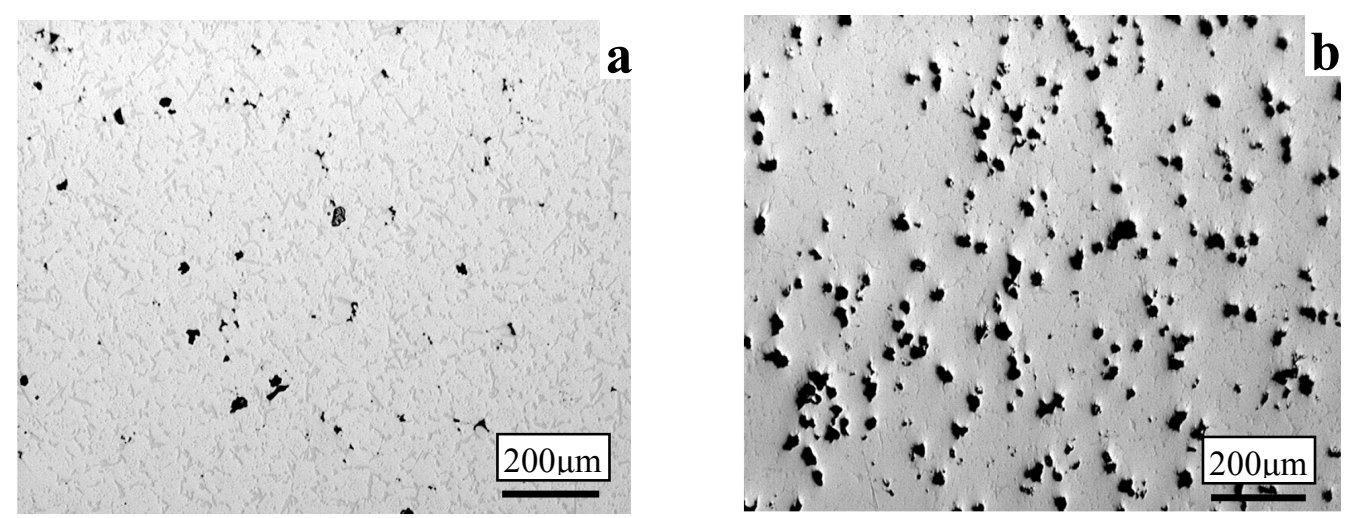

FIGURE 1. a) Stellite 6 and b) Stellite 21 in the as-received condition, showing differing porosity levels.
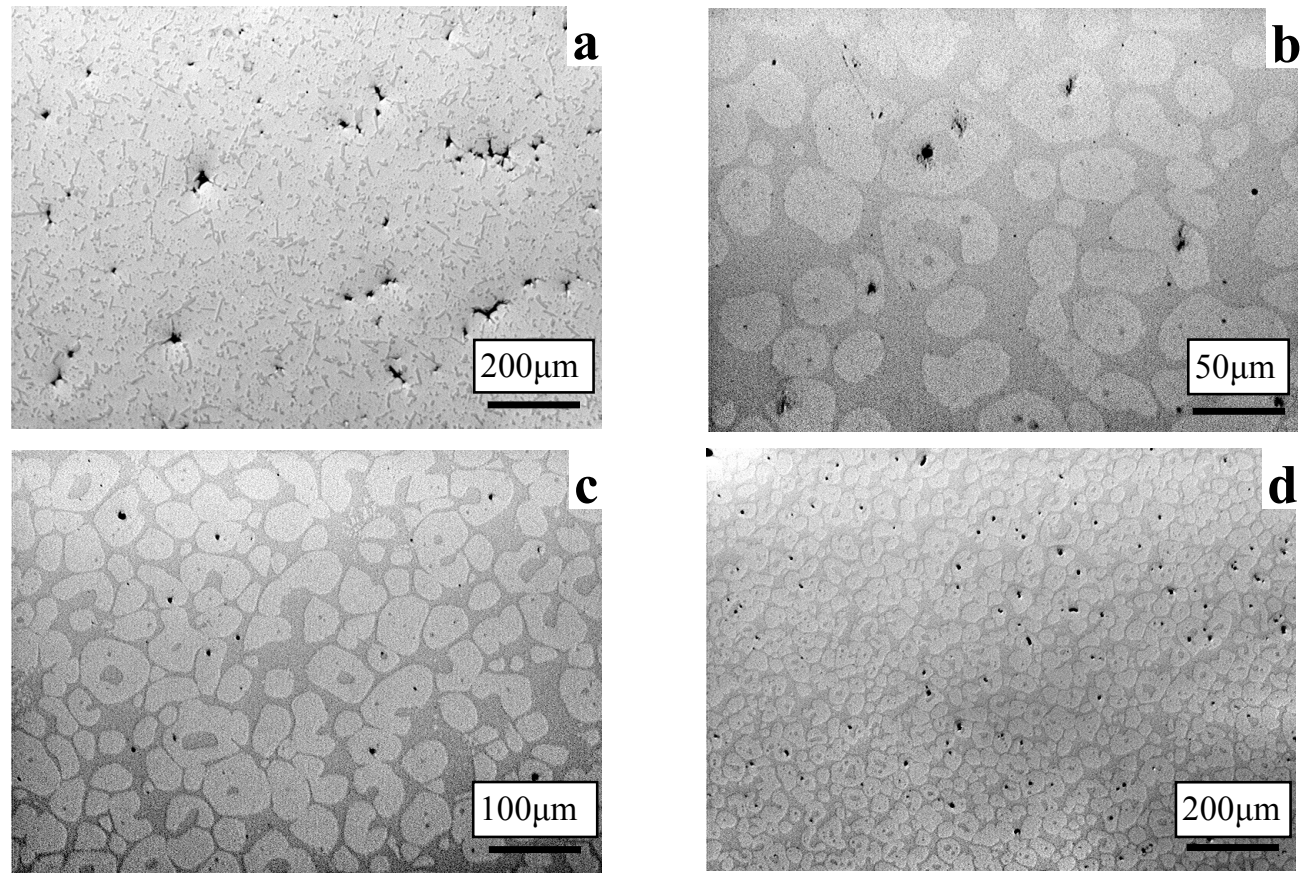

FIGURE 2. Optical micrographs of the $\mathrm{S} 6$ alloy isothermally heat treated for 5 minutes at a) $1330^{\circ} \mathrm{C}, \mathrm{b}$ ) $1340^{\circ} \mathrm{C}$, c) $1350^{\circ} \mathrm{C}$, d) $1360^{\circ} \mathrm{C}$.

Candidate thixoforming temperatures for the two alloys were $1330-1360^{\circ} \mathrm{C}$ for $\mathrm{S} 6$ and $1345-1355^{\circ} \mathrm{C}$ for S21. Fig. 2 shows the microstructure of S6 at various holding temperatures. At $1330^{\circ} \mathrm{C}$, no liquid was present after 5 mins. At $1340^{\circ} \mathrm{C}$ and above, liquid was present and the microstructure evolved to give discrete spheroids surrounded by liquid; the required microstructure for thixoforming. ${ }^{\circ}$ (3) selected as the thixoforming temperature as it is generally good practice to thixoform at as low a thixoforming temperature as possible whilst still obtaining die filling; this minimizes shrinkage effects and die wear. For S21, all the heat treatment temperatures produced spheroidal solid particles with contiguous liquid but there was less liquid 
present than in the S6 samples. This arises because of the reduced carbon content and therefore the reduced amount of eutectic (which forms liquid). A thixoforming temperature of $1350^{\circ} \mathrm{C}$ was selected for this alloy.

\section{Heating Schedule Trials and Thixoforming}

For the S6 alloy, a simple disc shaped die cavity was used with changes in section and sharp corners to indicate the ability of the semi-solid material to fill the die. The die machining marks were reproduced in the outer ring of the component as shown in Fig. 3, indicating the potential to produce complex shapes using this technique. There was oxide present on the surface despite the use of cover gas. In industrial practice, techniques have been established to remove this by skimming the surface as the material enters the die.

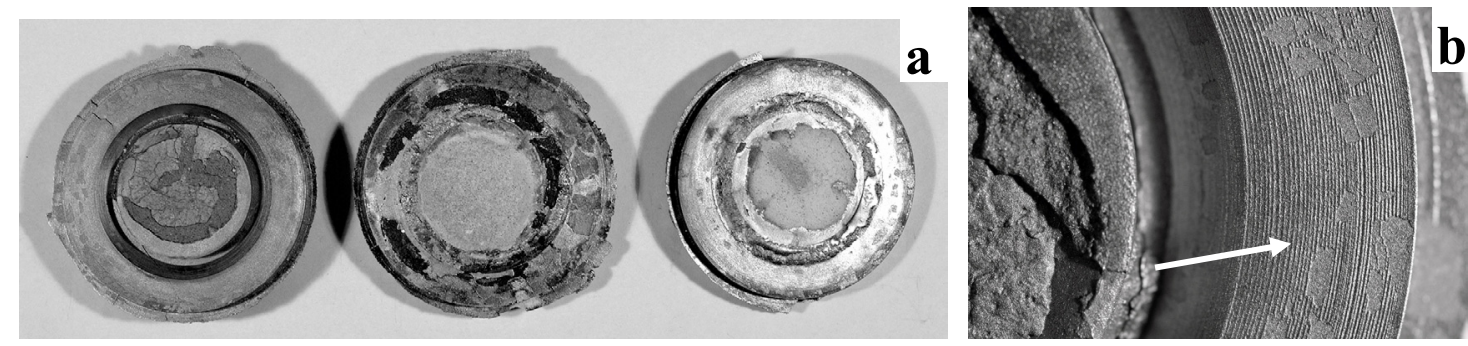

FIGURE 3. a) Appearance of three of the $S 6$ thixoformed components and b) Image of the outer ring of the component showing that the machining marks on the die surface have been reproduced.

The microstructures in the thixoformed component at the centre, mid-radius and edge of the component are shown in Fig. 4.

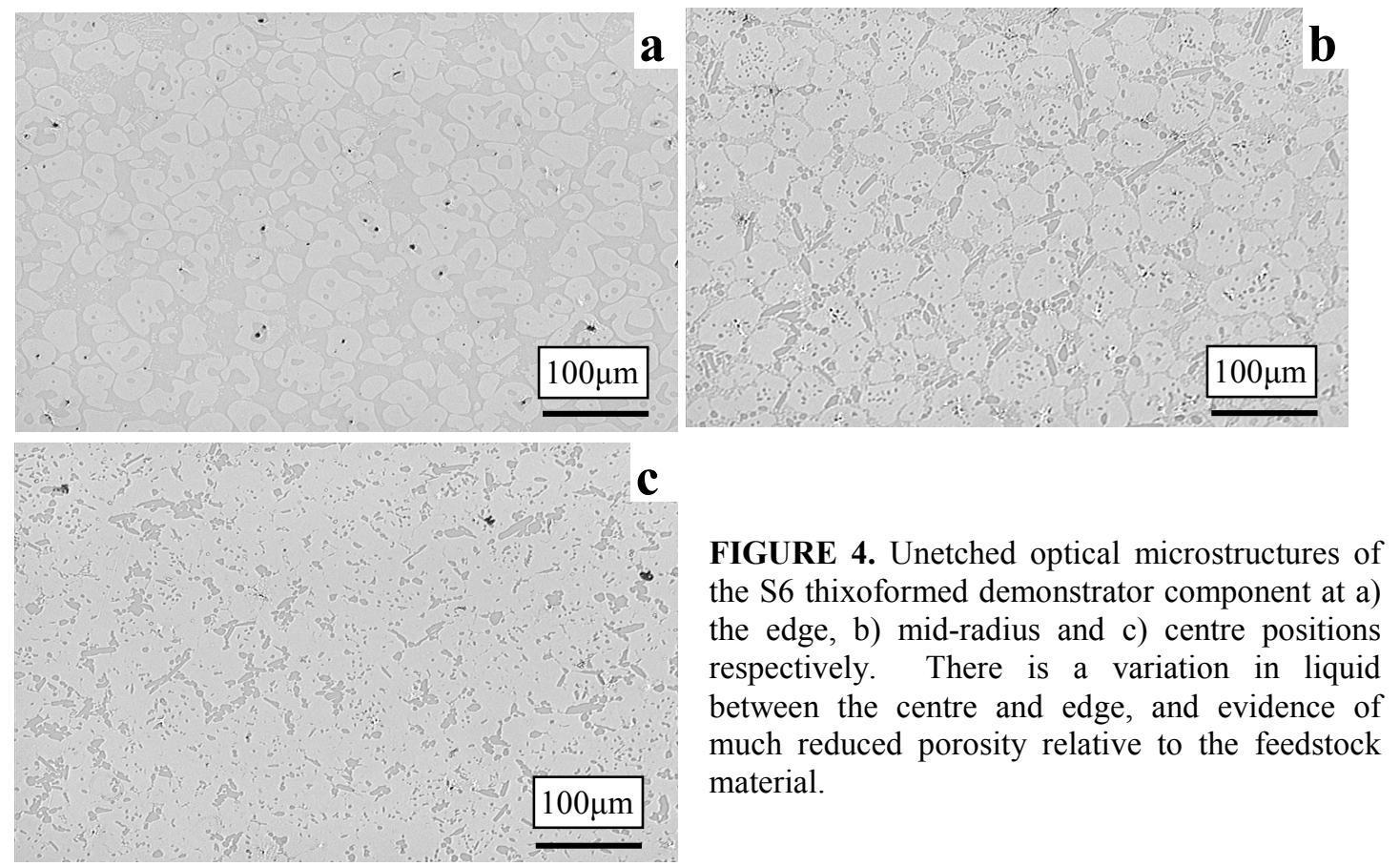

More liquid is evident at the edge. This arises from the non-uniform microstructure in the partially remelted slug prior to thixoforming. The heating schedule could be 
refined to reduce this variation and hence inhomogeneities in the final component. The carbides present in the starting material (Fig. 1) may have reprecipitated but in a form too fine to be resolvable with optical microscopy at these magnifications. The thixoforming has not had a deleterious effect on the hardness as will be shown later. The porosity level in the thixoformed component taken at five positions along the sample radius and determined by image analysis was approximately 0.2 area\%. This indicated that thixoforming was effective in virtually eliminating the porosity present in the feedstock material.

For S21, a star-shaped component with several protrusions, sharp corners and changes in section was produced. The microstructure was more uniform than for the S6 demonstrator (Fig. 5).

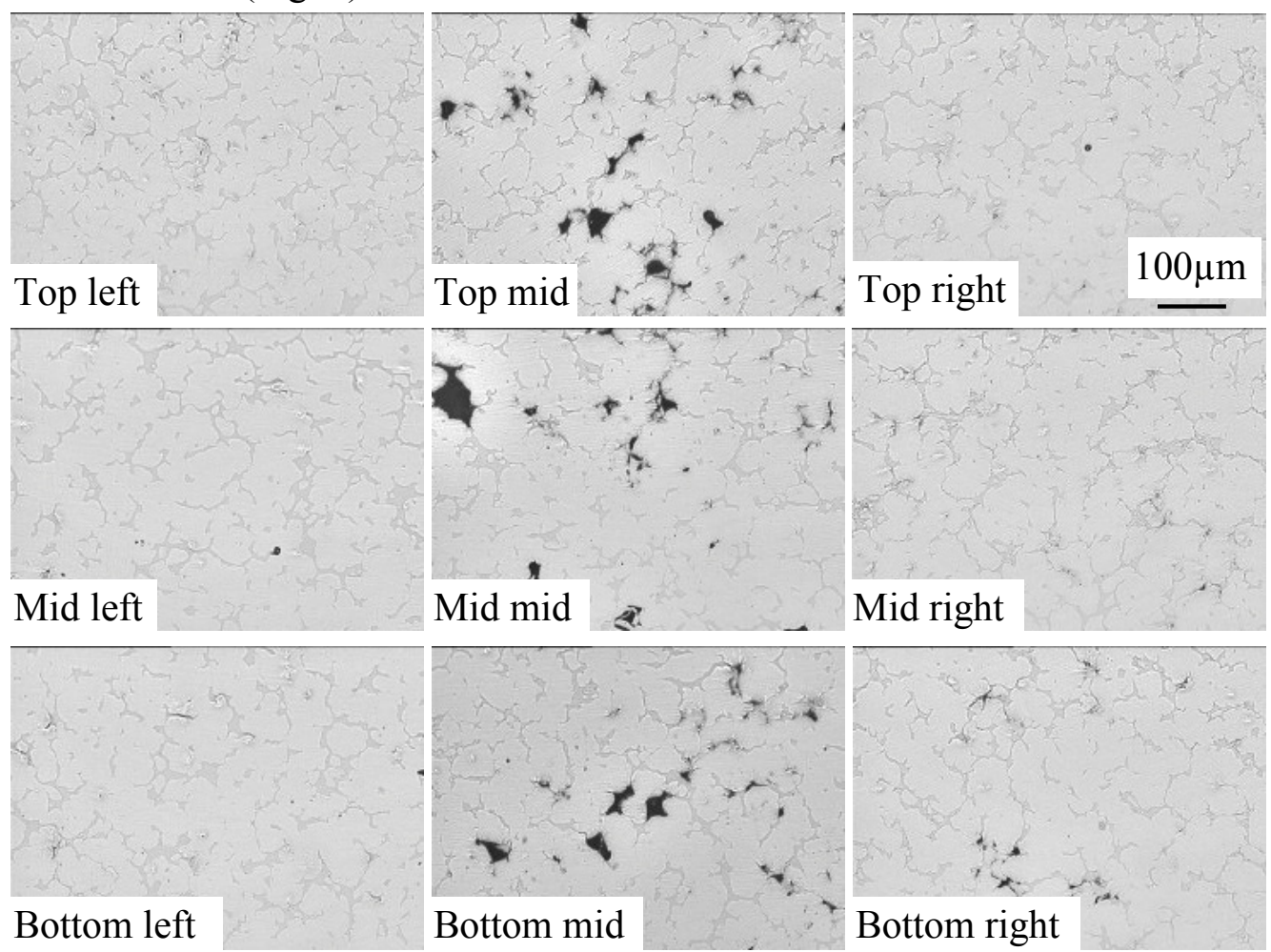

FIGURE 5. Unetched optical microstructures at various positions in the heat treatment sample slug. The microstructure consists of relatively spheroidal grains surrounded by a contiguous layer of liquid.

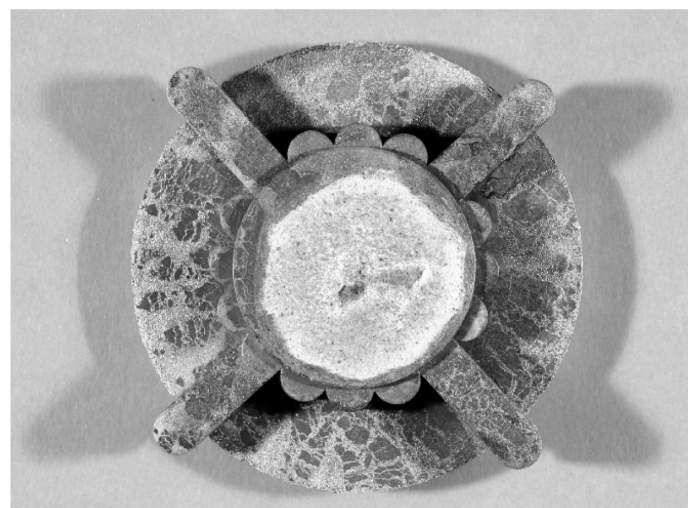

FIGURE 6. Appearance of the $\mathrm{S} 21$ thixoformed component.

This was due to the relative uniformity of the microstructure in the slug prior to forming as shown in Fig 5. The component is shown in Fig. 6. The porosity levels in the thixoformed component were $\sim 1.75$ area $\%$ at the edge, 0.75 area $\%$ at the mid-radius position and between 1 and 7 area $\%$ at the centre. The relatively high levels were associated with regions where the material had not flowed laterally. Again overall 
these results indicate that thixoforming can be effective in reducing the porosity in consolidated powder feedstock material. Hardness values in the thixoformed S6 material ranged between $43-46 R_{c}$. This compares with a specification value of 39-43 $R_{c}$. For $S 21$, the range was $38-41 R_{c}$ compared with a specification of $30-35 R_{c}$.

\section{CONCLUDING REMARKS}

Thixoformable feedstock can be produced from atomized and consolidated powders of the high temperature $\mathrm{Co}-\mathrm{Cr}$ alloys Stellite 6 and Stellite 21. Thixoforming temperatures were $1340^{\circ} \mathrm{C}$ for S6 and $1350^{\circ} \mathrm{C}$ for S21. Demonstrator components were produced using graphite dies and heating to the semi-solid state in $\sim 6$ minutes. The microstructures exhibited variations in the liquid content from the centre of the component to the edge. Porosity in the S6 components was approximately 0.2 area\%, indicating that thixoforming had been effective in virtually eliminating the porosity present in the sintered feedstock. Porosity in the S21 thixoformed component was greater, but only in regions where lateral flow of the semi-solid slurry had not occurred. The hardness values taken at various locations in the components were 43$46 \mathrm{R}_{\mathrm{c}}$ for the $\mathrm{S} 6$ alloy and $38-41 \mathrm{R}_{\mathrm{c}}$ for the $\mathrm{S} 21$ alloy. These values are above the specification for this alloy.

\section{ACKNOWLEDGEMENTS}

Thanks are due to Deloro Stellite for the provision of material, to Dr Danie de Wet and Dr Jim Wu of Deloro Stellite for their support and helpful discussions, and to the Department of Engineering Materials at the University of Sheffield for the provision of laboratory facilities.

\section{REFERENCES}

1. D. B. Spencer, R. Mehrabian and M. C. Flemings, Metall. Trans., 3;1925-32(1972).

2. P.Crook, Adv Mater Process 145, 27-30(1994).

3. T. Fujii, R. J. Dashwood and H. B. McShane, Proc. $7^{\text {th }}$ Int. Conf. Semi-Solid Processing of Alloys and Composites, edited by Y. Tsutsui, M. Kiuchi and K. Ichikawa, Tsukuba, Japan, Sept 2002, National Institute of Advanced Industrial Science and Technology and Japan Society for Technology of Plasticity, pp.191-96.

4. C. M. Chen, C. C. Yang and C. G. Chao, Mater. Sci. Eng. A, 366;183-194(2004).

5. P. Kapranos, D. H. Kirkwood and C.M. Sellars, Proc. Inst. Mech. Eng. Part B- J. Engineering Manufacture, 207(1);1-8(1993).

6. P. Kapranos, R. C. Gibson, D. H. Kirkwood, P. J. Hayes and C. M. Sellars, Materials Sci. and Technol. 12(3);274-78(1996).

7. M. A. Ashworth, J. C. Bryar, M. H. Jacobs and S. Davies, Powder Metall. 42;243-249(1999). 